Esta revista forma parte del acervo de la Biblioteca Jurídica Virtual del Instituto de Investigaciones Jurídicas de la UNAM

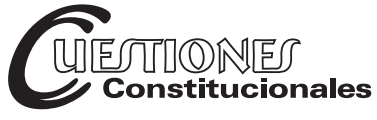

Revista Mexicana de Derecho Constitucional Núm. 44, Enero-Junio 2021

ISSN (versión electrónica): 2448-4881

\title{
La educación: Hacia un derecho humano
}

\author{
Education: Towards a human right
}

Recepción: 14 de julio de 2020

Aceptación: 1 de octubre de 2020

\author{
Raúl CONTRERAS BustAMANTE*
}

RESUMEN: Al derecho a la educación se le ha visto como un derecho sujeto a una fuerte connotación social que hace que se analice su viabilidad en el contexto de las implicaciones económicas y sociales, por tanto, debe transitar a un derecho humano cuyo cumplimiento no dependa de las circunstancias indicadas, sino de la exigencia de ser un derecho de la persona necesario para su desarrollo individual. De poco sirven los derechos si la mayoría de la sociedad carece de elementos cognoscitivos para acceder a ellos, entenderlos, ejercerlos y defenderlos cuando las instancias gubernamentales se los niegan. El derecho a la educación debe constituirse como un concepto jurídico prioritario, ubicado de manera inmediata después del derecho a la vida y a la libertad.

Palabras clave: derecho a la educación, educación, derechos sociales, derechos humanos.
ABSTRACT: The right to education has been seen as a right subject to a strong social connotation that makes its viability to be analyzed in the context of economic and social implications, therefore, it must become a human right whose fulfilment does not depend on the indicated circumstances, but on the requirement of being a right of the person necessary for his or her individual development. Rights are of little use if the majority of society lacks the cognitive elements to access them, understand them, exercise them, and defend them when they are denied by government agencies. The right to education must become a priority legal concept, immediately after the right to life and liberty.

Keywords: Right to Education, Education, Social Rights, Human Rights.

* Doctor en derecho por la Universidad Autónoma de México y por la Universidad de Salamanca, España. Profesor de Derecho constitucional de la Facultad de Derecho de la UNAM. Investigador nacional nivel I. Actualmente es director de la Facultad de Derecho de la UNAM. Correo electrónico: contrerasdf@gmail.com ORCID: 0000-0002-9786-2517. 
Esta revista forma parte del acervo de la Biblioteca Jurídica Virtual del Instituto de Investigaciones Jurídicas de la UNAM

SUMARIO: I. Introducción. II. La evolución de la educación. III. La educación como derecho social. IV. La educación como derecho humano. V. Conclusiones.

\section{INTRODUCCIÓN}

La educación, accesible para todas las personas sin discriminación alguna, se ha venido convirtiendo en un concepto esencial para el desarrollo de los seres humanos, así como de las sociedades de nuestro tiempo. ${ }^{1}$

La educación ha sido producto de luchas sociales que han tenido por objetivo que se le reconozca como un derecho. Sabemos que los derechos humanos, en la concepción moderna, abarcan tanto a los derechos civiles y políticos, como a los derechos económicos, sociales y culturales. Por eso existe un Pacto Internacional de Derechos Civiles y Políticos, adoptado el 16 de diciembre de 1966 por la Asamblea General de las Naciones Unidas, y el cual entró en vigor el 23 de marzo de 1976; y también un Pacto Internacional de Derechos Económicos, Sociales y Culturales, adoptado el mismo día 16 de diciembre de 1966 por la Asamblea General, pero entrando en vigor el 3 de enero de 1976. Desde entonces, y teniendo como base la Declaración Universal de los Derechos Humanos, adoptada por la Asamblea General el 10 de diciembre de 1948, ha quedado claro que los derechos humanos mantienen esta doble faceta.

Esta situación, sin embargo, no ha sido siempre así, antes de esos instrumentos internacionales hemos debatido el alcance que debe dársele a la educación desde el punto de vista de los derechos. Por ello, en el presente artículo queremos subrayar la evolución de la educación desde años anteriores a los Pactos Internacionales, buscando sus orígenes, su connotación social y su conquista a través de etapas revolucionarias, pero adentrándonos en su evolución como derecho humano, pues así le han caracterizado los instrumentos internacionales a los que ya hicimos referencia, pero, también, los textos constitucionales.

Queremos hacer un trazo de la educación enfocándonos en su noción de derecho social, con una connotación que se abre dejando de ser propia de sectores de élite para llegar a toda la sociedad, pero que también queda

\footnotetext{
1 Este texto constituye un producto de la investigación principal que he venido desarrollando sobre el derecho a la educación en la Universidad de Salamanca.

Cuestiones Constitucionales, Núm. 44, Enero-Junio 2021

ISSN: 2448-4881
} 
Esta revista forma parte del acervo de la Biblioteca Jurídica Virtual del Instituto de Investigaciones Jurídicas de la UNAM

enmarcada por los aspectos económicos, sociales y de desarrollo en general. Su surgimiento con base en una revolución social, como sucedió en nuestro país, por ejemplo, pone en evidencia que ha estado más presente su faceta social, con todas las implicaciones económicas y políticas que ello produce, que su comprensión como un derecho que surge de la persona, que puede exigirse y que el estado debe cumplir.

El objetivo de este artículo es enfocar de una mejor manera el derecho a la educación, dejar de verlo como un derecho sujeto a una fuerte connotación social que hace que se analice su viabilidad en el contexto de las implicaciones económicas y sociales, para pasar a ser un derecho humano cuyo cumplimiento no depende de las circunstancias sociales, sino de la exigencia de ser un derecho de la persona necesario para su desarrollo individual. Se busca contribuir a consolidar esta noción y la idea entre los constitucionalistas y demás estudiosos del Derecho, de que se debe catalogar como un concepto jurídico prioritario, ubicado casi de manera inmediata después del derecho a la vida y la libertad, como es nuestra posición.

En consecuencia, primero abordaremos la evolución de la educación durante etapas previas a su noción de derecho social (II), para después indicar sus características como derecho social (III). Enseguida nos centraremos en la educación como derecho humano señalando las consecuencias de esta categorización (IV), para terminar, exponiendo algunas reflexiones necesarias para que la educación se consolide como un derecho humano (V).

\section{LA EVOLUCIÓN DE LA EDUCACIÓN}

La educación - a lo largo de la historia - siempre estuvo reservada para las élites dominantes como la monarquía, la aristocracia y la iglesia, con el doble propósito de preparar y adoctrinar a los jóvenes para el acceso, ejercicio y sucesión del poder político y económico, y, al mismo tiempo, para cuidar que el conocimiento estuviese reservado a unos cuantos a efecto de poder mantener la dominación y sometimiento de las demás clases y castas sociales.

La educación y el conocimiento generan poder y, por tanto, era un recurso estratégico bien guardado y reservado para unos cuantos, bajo el principio de que el poder no se comparte ni se regala. 
Esta revista forma parte del acervo de la Biblioteca Jurídica Virtual del Instituto de Investigaciones Jurídicas de la UNAM

Con variantes que dependieron de la era y los cambios evolutivos de cada sociedad, a lo largo de los siglos la educación siempre fue un factor de desarrollo de la sociedad. Desde la antigüedad, cuando el Hombre primitivo entendió que la inteligencia y los conocimientos técnicos eran la mejor forma de evitar que las diferencias entre los hombres se resolvieran mediante la violencia y privilegiando el uso de la fuerza física (Bowen, Hobson, 1997), la utilización y ejercicio del conocimiento se convirtió en un instrumento que hizo posible que la vida en sociedad pudiera regirse a través de normas legales de convivencia, en lugar del mero sometimiento forzoso.

La necesidad de trasmitir el conocimiento fue el origen de la educación. Enseñar primero a quienes habrían de ser seleccionados para aprender el oficio o arte; y luego instruir y formar a quienes habrían de sucederlos en el control de sus empresas, para que adquirieran el conocimiento acumulado a través de la experiencia de la vida y el trabajo.

La trasmisión del pensamiento y del conocimiento fue creando cultura (Toynbee, 1981). Aquí es donde comienza a surgir la función del mentor o profesor, a quien se le encomendaba la formación de los educandos, para lo cual siempre se acostumbró a reclutar para estas tareas a las mentes más notables de cada período de la historia. La educación ha constituido siempre una pieza fundamental para la construcción, desarrollo y fortaleza de todas las civilizaciones.

La conjunción de inteligencia, conocimiento, educación y poder se convirtieron en los elementos esenciales que han servido para la preservación del poder político, el sometimiento, dominio, conducción y gobierno de la sociedad a lo largo de los siglos de vida social humana.

En la Edad Antigua, para los griegos (Jaeger, Werner, Paideia, 2001), y romanos (Barrow, R., 2006), la educación tuvo tintes heroicos y aristocráticos, siempre limitada al servicio de los ciudadanos libres y pudientes que representaban una pequeña élite, ya que no se incluía a las mujeres, esclavos ni a otros grupos desfavorecidos (Vergara, 1989).

En la Edad Media, la educación y sus beneficios se trasladaron de manera primordial a manos del alto clero (Jaeger, 2008). La Universidad - como la conocemos en la actualidad - es una creación que surge en la Edad Media, pero el acceso a ellas era solo permitido para la nobleza, el clero y un poco a miembros de la burguesía, porque se requerían altos 
Esta revista forma parte del acervo de la Biblioteca Jurídica Virtual del Instituto de Investigaciones Jurídicas de la UNAM

recursos económicos, es decir, en sus inicios las Universidades estuvieron al servicio de las clases dirigentes y las élites (Gadotti, 2003).

En el Renacimiento, el abanico educativo se abrió un tanto, pero solo alcanzó a incluir junto con la nobleza y el clero, a la aristocracia y la burguesía emergente (Gadotti, 2003). Al arribar la Ilustración, como resultado de la compilación y reinterpretación del conocimiento universal, la educación dejó de estar en poder exclusivo de la Iglesia, para servir a los intereses de la burguesía. Si bien en esta etapa luminosa del pensamiento se observaron signos de que se pretendió comenzar a educar al pueblo llano y que la educación dejara de ser un privilegio exclusivo de la aristocracia y el clero, pero esos impulsos no fueron suficientes (Luzuriaga, 1971).

A partir de entonces, la participación que ha tenido el Estado en la impartición de la educación es clave para entender su evolución (De Puelles Benítez, 1993).

Existía, al parecer, una indiferencia del Estado por la educación, especialmente la popular, dejándola como una prerrogativa propia de la iglesia. Eso sucedió, por ejemplo, en la Francia de los siglos XVI y XVII, en donde incluso el Estado tomó cierta distancia de la iglesia, pero dejó en manos de organizaciones religiosas la enseñanza básica. En otros Estados, en donde había un acercamiento entre Iglesia y Estado, este último adoptó un papel activo prestando su ayuda en la educación, como sucedió en Suecia.

Ya en la Edad moderna, ante la dinámica de intervención del Estado afirmando su soberanía en todos los ámbitos, se hace más visible su participación en la educación superior, que había quedado en universidades eclesiásticas, buscando participar de las regalías o en la formación de las élites que iban a dirigir el país. Esta incursión estatal no fue fácil, pues el esquema seguía la tendencia del modelo medieval y la reforma educativa no era de fácil introducción, por tanto, el Estado tuvo que incursionar con escuelas en nuevos ámbitos, como el militar, la ingeniería o la náutica, por señalar algunas.

En la época previa a la revolución francesa hubo una expansión de escuelas, sin embargo, la calidad de la educación no fue algo que resaltara, ni en este país ni en otros como Suiza, Holanda o Prusia. Lugares impropios, maestros sin formación, salarios insuficientes, era una constante.

En el siglo XIX, en pleno Estado liberal, la ilustración constituyó una fuente de ideas para la defensa frente a la opresión del Estado, por lo que ante el respeto a las libertades de los individuos era importante contar con 
Esta revista forma parte del acervo de la Biblioteca Jurídica Virtual del Instituto de Investigaciones Jurídicas de la UNAM

ciudadanos ilustrados que hicieran posible las nuevas ideas y un nuevo régimen. Así es como surgen los derechos naturales de las personas, los cuales se oponían a los abusos del poder, para limitarlo.

En estas circunstancias, era de esperarse que el Estado también fuera limitado en la educación, sin embargo, los acontecimientos de la revolución francesa cambiaron el rumbo de las cosas, ya que al atentar contra la iglesia nacionalizándole sus bienes eclesiásticos, con ello también se dio un golpe duro a la asistencia que ofrecían y a la educación que impartían. Por esta razón, el Estado tuvo que intervenir directamente en estas actividades sociales constituyéndolas en servicios públicos, abierto para todos. Era la oportunidad para que la educación fuera uniforme, que formara a la infancia y a la juventud, que tomara en cuenta los intereses de la sociedad y no solamente los de la iglesia, que los profesores fueran laicos. Desde entonces, se presentaron diversas disyuntivas. Se formaba a la élite de la nación o se elevaba el nivel cultural del pueblo, la instrucción pública se limitaba a la enseñanza primaria o incluía todo el sistema educativo nacional, siendo público y gratuito.

En el posterior desarrollo del siglo XIX quedó claro que la instrucción elemental y gratuita era para el pueblo, pero la educación superior era para las capas medias y altas de la sociedad, siendo onerosa. Sin embargo, la educación quedaba como una atribución del Estado, no como un derecho de la persona. Corresponderá al siglo XX cambiar el sentido de las cosas y perfilar una nueva concepción en la cual la instrucción, a secas y sin distingo de ningún nivel, llegue a todos.

\section{LA EDUCACIÓN COMO DERECHO SOCIAL}

Fue hasta el siglo XX en que la educación comenzó a ser concebida como la clave para la democracia y el progreso y se instituyó como un derecho social, que comenzó a ponerse al alcance de la mayoría de la sociedad como una conquista, no sólo de los grupos privilegiados.

En el siglo XIX tenemos la presencia de un Estado diverso al abstencionista, uno en que interviene y ejerce control en cuestiones económicas, pero también en cuestiones sociales convirtiéndose en un Estado social o de bienestar (García Pelayo, 1989). Junto a esta nueva noción apareció la del constitucionalismo social, toda vez que la importancia de las cues- 
Esta revista forma parte del acervo de la Biblioteca Jurídica Virtual del Instituto de Investigaciones Jurídicas de la UNAM

tiones sociales trascendió a los textos constitucionales, como programas sociales o aspiraciones populares.

En el caso mexicano, a partir de la promulgación de la Constitución de los Estados Unidos Mexicanos de 1917, la educación comenzó a dejar de ser instrumento exclusivo al servicio del poder y de exclusión favorable a las élites, para empezar a ser utilizado como un derecho articulador de equidad para tratar de alcanzar justicia social (Contreras Bustamante, 1989).

Como resultado de las luchas sociales que se generaron contra el latifundismo, el analfabetismo, la pobreza extrema y demás desigualdades sociales, la Revolución Mexicana empezó a forjar una ideología reivindicadora de tantas injusticias y a concebir a la educación como instrumento esencial para tratar de alcanzar la igualdad y la justicia social.

Por primera vez en el mundo, el artículo 3o. de la carta magna de Querétaro estableció en un texto de orden constitucional, que la educación deberá ser pública, gratuita, laica y de carácter obligatorio del Estado para proveerla.

La institucionalización de los derechos sociales fue una aportación mexicana a la doctrina del constitucionalismo, que permitió la incorporación del valor de la equidad en el orden constitucional (Contreras Bustamante, 1989). El derecho a la educación se convirtió en el derecho social por excelencia, debido a sus efectos transformadores y como un elemento indispensable para lograr la dignidad humana.

La aparición de los derechos sociales en el ámbito constitucional generó un efecto reproductor, porque muy rápido se reconoció su importancia y produjo un impacto muy importante en el mundo occidental.

Como sucede y se explica por la teoría de la constitución, la concepción de los derechos sociales logró su adopción en muchas constituciones y organizaciones internacionales. Después de nuestro país, siguió la constitución soviética de 1918, luego la alemana de Weimar de 1919 y —en ese mismo año- la Organización Internacional del Trabajo, los hicieron suyos (Contreras Bustamante, 1989).

En diversas constituciones europeas, como la alemana de 1949 o la italiana de 1947 o la francesa de 1958 o la española de 1978 se conserva la noción de estado social. Lo mismo aconteció en Latinoamérica. Bajo este movimiento, el derecho a la educación se le reguló en las constituciones como un derecho social, apareciendo con un amplio articulado. Ahí está la 
Esta revista forma parte del acervo de la Biblioteca Jurídica Virtual del Instituto de Investigaciones Jurídicas de la UNAM

Constitución de Argentina, Brasil, Chile, Colombia y Uruguay, por citar algunas (Valencia Carmona, 2003).

Luigi Ferrajoli considera que los Derechos Sociales son en el fondo expectativas de comportamientos ajenos, a los que corresponden obligaciones o deberes por parte del Estado (Ferrajoli, 2010). Estas reivindicaciones sociales obligaron a un cambio en la actividad del Estado, que tuvo que abandonar de manera progresiva su postura abstencionista y adoptar como propia la función social de su prestación (Pérez Luño, 2017).

En esencia, la doctrina explica que los Derechos Sociales no se limitan a tutelar individuos, sino que aspiran a proteger a las clases sociales, gremios o segmentos de la sociedad en condición social desfavorable.

André Hauriou sostiene que los derechos sociales no constituyen para los individuos un poder de actuar, sino facultades de reclamar determinadas prestaciones de parte del Estado: "De esta forma, la visión respecto a ellos se ensancha, del derecho-resistencia se pasa al derecho-confianza, y de la abstención del Estado, a su intervención" (Hauriou, André 1980).

A pesar del papel fundamental que juegan los derechos sociales en las sociedades modernas, debido a visiones neoliberales, esta clase de derechos muchas veces quedan reducidos a ser sólo normas programáticas de realización gradual y privados de mecanismos de garantía efectiva (García, 2015).

Carl Schmitt - en un tono un tanto despectivo - los denominaba derechos de esencia socialista, los cuales no eran ilimitados, "pues todo derecho a prestaciones es limitado", ya que dependen de que la organización estatal incorpore al individuo como titular del derecho (Schmitt, 1992).

Por su parte, Manuel García Pelayo los denominaba como "derechos y pretensiones a prestaciones del Estado", y ponía como ejemplos al derecho al trabajo, el derecho a la educación, entre otros (García Pelayo, 1984).

La evolución y el impacto de los Derechos Sociales han venido sufriendo los efectos de la teoría liberal que recomienda que el Estado no intervenga en la vida social y económica; motivo por el cual, y en virtud de la concepción de que la educación es parte de ellos, le ha restado fuerza para su implementación más pronta.

Estas concepciones garantistas que enaltecen el concepto de la educación como derecho humano, sin embargo, nos son únicas ni unitarias dentro del ámbito internacional, ya que existen otros enfoques diversos que consideran la educación no como un derecho humano, sino sólo como un 
Esta revista forma parte del acervo de la Biblioteca Jurídica Virtual del Instituto de Investigaciones Jurídicas de la UNAM

factor importante - dentro de otros muchos - para el desarrollo económico y social de los países (Vargas, 2017).

Estas visiones contrastantes - casi de carácter antitético- entre organismos internacionales respecto a la educación se pueden sintetizar de la manera siguiente. Por una parte, la visión humanista de la educación que sostiene la UNESCO, que es quien enarbola a la educación como un derecho humano, fundamental, esencial para el desarrollo de la persona, y, por el otro, el enfoque economicista de las políticas educativas para el desarrollo, que sustentan la Organización para la Cooperación y el Desarrollo Económico (OCDE), el Banco Mundial (BM), el Banco Interamericano de Desarrollo (BID) y el Fondo Monetario Internacional (FMI), todos ellos organismos internacionales financieros que consideran la educación de forma más limitada, como uno más de los factores que estimulan el crecimiento económico de los países. Un factor muy importante, si bien es cierto, pero sólo uno más.

Durante las últimas cuatro décadas, el mundo ha sido testigo y víctima de las políticas públicas y enfoques diversos que han emanado de estos organismos internacionales de corte financiero, quienes establecieron e impusieron programas económicos en los países que tuvieron que recurrir a su auxilio y financiamiento, que en gran medida determinaron el estado actual de sus sistemas educativos.

Diversos académicos e investigadores de la materia educativa cuestionan los resultados de la intervención de dichos organismos internacionales financieros en los procesos relativos a la educación (Rizvi, Lingard, 2013).

Existen evidencias que demuestran que estas instituciones financieras equivocaron el rumbo de muchas de las políticas impuestas y de manera tardía llegaron a aquilatar el valor que implica para las naciones la educación, hasta que tuvieron a aceptar que más que un gasto, la educación es una inversión clave para erradicar la pobreza (Santos, 2015).

Estas voces críticas se oponen a la dependencia y subordinación de la educación al interés económico. No se puede negar el proceso de globalización que también vive la materia educativa, pero existe la necesidad de no perder de vista un tinte de contenido social. En este contexto, se habla de la misión social que tiene la educación de preparar personas con una preparación plena y suficiente para comprender el mundo que los rodea y también el compromiso que las políticas educativas deben asumir con 
Esta revista forma parte del acervo de la Biblioteca Jurídica Virtual del Instituto de Investigaciones Jurídicas de la UNAM

la sociedad en que se imparte, hacia el logro de la equidad y la igualdad (Santos Rego, 2009).

Se trata de opiniones de corte humanista que provienen de mentes muy reconocidas, que consideran que la educación más que fomentar la competitividad económica, debe contribuir en primer lugar al desarrollo integral de las personas y desde luego al avance cultural y moral de las sociedades.

Según esta visión humanista — que podría incluso ser holística - de la educación, ésta debe contribuir a lograr un nuevo modelo de desarrollo alentado por principios como el cuidado del medio ambiente, la promoción de la paz y la no violencia, la equidad y la justicia social. Esta visión de la educación propone dejar atrás el utilitarismo y el economicismo de cortas miras, para integrar las dimensiones múltiples de la existencia humana, con la intención de que avance hacia estratos mejores de desarrollo (UNESCO 2015).

En esta visión humanista, la educación aparece también como la principal herramienta para la construcción de un mundo más libre e igualitario $\mathrm{y}$, en consecuencia, más pacífico y próspero.

Dentro del concepto de la necesidad de generar condiciones plenas de igualdad para que todas las personas puedan acceder a la educación, hoy no puede dejar de considerarse también el acceso inequitativo a los recursos tecnológicos, a la conectividad al internet y a los conocimientos de vanguardia, que son aspectos que profundizan la desigualdad social y la exclusión, en lugar de la integración, tanto al interior de los países, como en relación con el sistema mundial.

Las llamadas "brechas digitales" y "brechas cognitivas", son fenómenos que conforman un sistema educativo desigual a nivel interno de los países y que al mismo tiempo los someten al dominio de aquellos países con mayor desarrollo económico y tecnológico. La "brecha cognitiva" se presenta por la existencia de diferentes "capacidades cognitivas" entre sociedades que son producto de situaciones inequitativas.

La suspensión de las actividades presenciales con motivo de la pandemia que está azotando al mundo obligó al cierre de miles de escuelas. La necesidad de tener que impartir clases a distancia a través de herramientas tecnológicas, vino a dejar al desnudo también las graves desigualdades sociales que provocan que muchos estudiantes se queden atrás por falta de acceso al internet y de dispositivos que lo permitan. 
Esta revista forma parte del acervo de la Biblioteca Jurídica Virtual del Instituto de Investigaciones Jurídicas de la UNAM

Al paso del tiempo y derivado de los procesos de globalización, los organismos internacionales financieros han tenido que reconocer la importancia de la educación para la contribución al crecimiento económico y como un medio para conseguir un incremento en el bienestar general, convirtiéndose ambos en materia de su atención.

En un principio la educación era considerada como un mero instrumento de política económica, pero en la actualidad, la función educativa se entiende en relación con el contexto social, económico y cultural en que se presenta, destacando siempre la interacción entre las políticas educativas y otras políticas públicas.

Como medida para impulsar el desarrollo, los organismos internacionales de corte financiero procuran ahora estimular la mejora en la calidad de la educación; la búsqueda de la igualdad de oportunidades educativas; el combate a la marginalización de los jóvenes; el desarrollo de esquemas democráticos y eficientes de administración educativa; y de forma muy particular, privilegiar la relación entre la educación y el empleo en la formación para la vida laboral. Sin embargo, siempre fomentando que el sistema educativo sea capaz de proveer a un mercado de trabajo flexible a trabajadores competentes, capaces de desarrollarse y adaptarse a los cambios rápidos propiciados por la restructuración económica y por los avances tecnológicos.

Por ejemplo, para la Organización para la Cooperación y el Desarrollo Económicos (OCDE), la educación se ha convertido en un elemento clave para medir el grado de desarrollo económico y social de los países miembros. El Programa para la Evaluación Internacional de Alumnos (PISA) se propone como una prueba global que permita comparar los logros de los sistemas de educación con los de otros países miembros para "probar las competencias de los estudiantes de forma directa, mediante una prueba acordada a nivel internacional" (Schleicher, 2018).

\section{LA EDUCACIÓN COMO DERECHO HUMANO}

Los derechos sociales se presentan hoy como auténticos derechos que aspiran a proteger a todas las personas, ya no sólo como parte de un núcleo o clase y con la aspiración de asegurar a todos - sin discriminaciones o limitantes de cualquier especie- el acceso a la salud, alimentación, vi- 
Esta revista forma parte del acervo de la Biblioteca Jurídica Virtual del Instituto de Investigaciones Jurídicas de la UNAM

vienda y también a la educación, donde a cada paso se amplía la demanda obligatoria para el Estado.

Roberto Gargarella sostiene que: "Los derechos sociales se volvieron un instrumento más para interpelar, exigir y actuar" (Gargarella, Etchicury, 2011).

El paso de la educación de un derecho social a un derecho humano no ha sido fácil. Ha habido toda una evolución hacia su reconocimiento. Ha tenido que recorrer un proceso de superación de las exclusiones, antes de consolidarse como derecho humano. De esta manera, siguiendo a Katarina Tomasevsky, anterior Relatora para la educación de la ONU, este proceso consta de tres etapas. En la primera de ellas, se advierte que la educación debe llegar a aquéllos a quienes se les ha negado históricamente, como los pueblos indígenas o los no ciudadanos, o quienes siguen estando excluidos, como lo son los servidores domésticos o los integrantes de comunidades nómadas, aunque esto entraña una segregación en cuanto que se les confina en escuelas especiales. En la segunda etapa se requiere abordar la segregación educativa y avanzar hacia la integración, en la cual los grupos recién admitidos deben adaptarse a la educación, como podría ser la existencia de lenguas desconocidas para los nuevos grupos. En la tercera etapa se exige una adaptación de la enseñanza a la diversidad de los aspectos del derecho a la educación (Tomasevsky, 2020).

Por nuestra arte, somos de la opinión que, en el año de 1948, la Declaración Universal de Derechos Humanos dio un salto hacia adelante y reconoció al derecho a la educación con la condición de ser un derecho humano y fundamental, idea que ha sido recogida y desarrollada después por otros importantes instrumentos internacionales (Gargarella, Etchicury, 2011).

La importancia del fenómeno educativo se ha venido consolidando a lo largo del tiempo, al grado de que en la actualidad existe una aceptación de manera casi unánime de parte de los Estados — sobre todo los más desarrollados - que ubican a la educación como un elemento fundamental para la preparación de las personas, para que puedan integrarse al mercado laboral y contribuyan de manera positiva al progreso social y al desarrollo nacional.

La Organización de las Naciones Unidas para la Educación, la Ciencia y la Cultura (UNESCO) organismo especializado de las Naciones Unidas, ha sido la organización internacional precursora que ha dado impulso para 
Esta revista forma parte del acervo de la Biblioteca Jurídica Virtual del Instituto de Investigaciones Jurídicas de la UNAM

tratar de consolidar la idea de que el acceso a la educación es un derecho humano de carácter fundamental. ${ }^{2}$

En el primer párrafo de la Observación General No. 13 del Comité de Derechos Económicos, Sociales y Culturales de Naciones Unidas, se establece: "Como derecho del ámbito de la autonomía de la persona, la educación es el principal medio que permite a adultos y menores marginados económica y socialmente salir de la pobreza y participar plenamente en sus comunidades". ${ }^{3}$

Esta idea ha sido desarrollada en diferentes eventos de carácter internacional y avalada por múltiples convenciones y acuerdos como: la Conferencia General de la Organización de las Naciones Unidas para la Educación, la Ciencia y la Cultura; el Pacto Internacional de Derechos Económicos, Sociales y Culturales; la Conferencia Internacional sobre Planificación de la Educación; la Convención sobre los Derechos del Niño; la Declaración Mundial sobre Educación para Todos; la Declaración y Programa de Acción de Viena y la Conferencia Mundial de Derechos Humanos; en los diversos Foros Mundiales sobre la Educación; la Declaración Americana de los Derechos y Deberes del Hombre; el Protocolo Adicional a la Convención Americana sobre Derechos Humanos en Materia de Derechos Económicos, Sociales y Culturales — también conocido como Protocolo de San Salvador -; la Carta Africana sobre los Derechos Humanos y de los Pueblos; la Carta Africana sobre los Derechos y el Bienestar del Niño, por citar a los más destacados instrumentos internacionales de gran trascendencia para el tema educativo, que han enarbolado de forma clara y contundente que "la educación es un bien público", además de un "derecho humano fundamental".

De acuerdo con la conveniencia de consolidar a la educación como derecho humano, desde un enfoque jurídico, científico y humanista, nuestro punto de vista se inclina por la visión de las Naciones Unidas, que es

2 La evolución del reconocimiento del Derecho a la Educación se reforzó con el establecimiento de la Organización de las Naciones Unidas para la Educación, la Ciencia y la Cultura (UNESCO), cuya Constitución fue aprobada en Londres, el 16 de noviembre de 1945.

3 La Observación General número 13 del Comité de Derechos Económicos, Sociales y Culturales de la Organización de las Naciones Unidas, señaló de manera expresa que el Derecho a la Educación es uno más de los derechos humanos y se discutió y aprobó durante el vigésimo primer período de sesiones, celebrado del 15 de noviembre al 3 de diciembre de 1999. 
Esta revista forma parte del acervo de la Biblioteca Jurídica Virtual del Instituto de Investigaciones Jurídicas de la UNAM

acorde a los principios y postulados de la doctrina de los derechos fundamentales.

Sostenemos que hay que luchar para que la educación sea humanista y no sólo tenga el carácter técnico o especializado. Educar para la vida y no solo formar para el trabajo. Las condiciones cambiantes de la vida social requieren de personas preparadas para reinventarse ante los cambios y con una clara conciencia social de cuál es su papel dentro de la sociedad y el medio ambiente. Educar para una vida digna y para contribuir al desarrollo social, la paz y la armonía.

Además, como todo derecho, hay que reconocer que el derecho a la educación supone obligaciones. El derecho a la educación —en sus efectos habilitantes - debe comprender la obligación de ser recíproco; se tiene que comprender y aceptar que si me educan tengo la obligación de educar. Implica que quien la recibe adquiere al mismo tiempo una carga de responsabilidad, respeto y consideración con los demás. La obligación que nace del derecho a la educación representa de manera intrínseca la construcción de una mejor ciudadanía.

Por tal motivo, consideramos que los principios y acuerdos que han sido formulados y suscritos por la inmensa mayoría de los países configuran reglas jurídicas plenas conforme al principio de la convencionalidad internacional. En consecuencia, todas las obligaciones que los Estados firmantes han convenido se deben cumplir para hacer efectivo el derecho humano a la educación.

El Comité de Derechos Económicos, Sociales y Culturales de las Naciones Unidas ha señalado de qué manera se tendrán que ir dando cumplimiento las disposiciones adquiridas por las naciones, en uso de sus facultades soberanas e independientes. Deberá ser bajo cuatro principios que consisten en: la disponibilidad, la accesibilidad; la aceptabilidad y la adaptabilidad.

Esto es así porque, además, las convenciones internacionales establecen de manera expresa que existirán procesos dinámicos para la vigilancia y averiguación de las violaciones en su aplicación, respeto y garantía - ya sea por obra o por omisión- e incluso existen estipulaciones que advierten a los Estados parte, que en caso de incumplimiento podrían ser objeto de prevenciones serias e importantes. 
Esta revista forma parte del acervo de la Biblioteca Jurídica Virtual del Instituto de Investigaciones Jurídicas de la UNAM

En tal virtud, de acuerdo con los criterios establecidos por las Naciones Unidas, el derecho a la educación ya debe considerarse que tiene características de ser exigible y justiciable.

El Comité de Derechos Económicos, Sociales y Culturales de las Naciones Unidas ha señalado de manera clara que si bien los objetivos de establecer el derecho a la educación — como derecho humano, de carácter fundamental y objeto de garantías de orden jurídico- deben ponerse en práctica de manera gradual y tratando de superar las restricciones y limitaciones generadas por la escasez de los recursos financieros disponibles que existen en cada Estado, esto no es óbice para omitir el cumplimiento de las obligaciones contraídas, a efecto de lograr el cumplimiento efectivo de este derecho.

Para poder contribuir a la consolidación filosófica del derecho a la educación como derecho humano, resulta conveniente hacer algunas reflexiones respecto de cómo el proceso educativo constituye un elemento esencial para alcanzar la dignidad humana, que es el valor supremo de los derechos fundamentales.

La evolución del concepto de los derechos humanos ha incorporado la idea de la dignidad como elemento indispensable para el uso y disfrute de los mismos. La sociedad moderna ya no puede conformarse con la simple enunciación de los derechos, si estos no vienen acompañados de otros elementos que brinden calidad a la vida de las personas. La vida misma, la igualdad, el ejercicio de las libertades, el acceso al disfrute de la propiedad, solo pueden considerarse como derechos efectivos y plenos, si quien los ejerce puede hacerlo con dignidad.

El jurista Ernesto Brenda define la idea de la dignidad humana, como: "La capacidad abstracta y potencial del ser humano para realizarse como tal" (Brenda, 1996).

Como ya se ha dicho, la Declaración Universal de Derechos Humanos reconoce una relación intrínseca entre el reconocimiento de los derechos humanos y el valor de la dignidad como camino para alcanzar la libertad, la justicia y la paz.

Con base a esta concepción se han venido construyendo los cimientos sobre los cuales se han establecido diversos instrumentos jurídicos internacionales, con el fin de proteger a las personas y permitir su desarrollo.

Por eso se ha dicho de manera recurrente, el ejercicio pleno de los derechos humanos debe ir acompañado siempre del desarrollo del concepto 
Esta revista forma parte del acervo de la Biblioteca Jurídica Virtual del Instituto de Investigaciones Jurídicas de la UNAM

de dignidad, pues: "es precisamente en relación con la tutela, protección y promoción de la dignidad que alcanzan una dimensión moral" (Martínez Bulle Goyri, 2013). Ésta es la doctrina que ha estado presente en muchos de los autores que han abordado la idea de dignidad.

Estas ideas han tenido un peso muy importante al concebir en la actualidad a la dignidad y a pesar de ser diferentes en algunos aspectos cruciales, también tienen un punto de encuentro: los valores de la libertad y la justicia.

Estas dos facultades o capacidades del ser humano que dotan de contenidos a la idea de dignidad se expresan y perfeccionan a través de la autodeterminación. El derecho a la educación se coloca como un elemento central en la defensa de la dignidad de las personas, porque si se quiere favorecer la capacidad de autodeterminación, resulta indispensable el acceso a la educación y la cultura a todas las personas, para que se les permita allegarse de información, conocimientos y preparación que las sensibilice y refuerce en sus capacidades, como condición indispensable de la dignificación a través del conocimiento.

Podemos afirmar, por tanto, que, sin el acceso a una educación garantizada, plena y de calidad, una persona no podrá vivir con dignidad dentro de la sociedad.

El derecho a la educación es un derecho de carácter habilitante, indispensable para poder lograr el conocimiento, comprensión, ejercicio y defensa de todos los demás derechos inherentes a la persona.

Es un derecho que posibilita a una persona para que, una vez adquirido el conocimiento, le sea viable entender, ejercer, activar y defender; hace efectivas las demás garantías y derechos que están reconocidos, concebidos y establecidos en las Constituciones y los Tratados Internacionales.

En este contexto, la educación adquiere la connotación de ser un instrumento indispensable para lograr la equidad y la igualdad social en cuanto al acceso real a todas las oportunidades de desarrollo.

El concepto según el cual la educación es un pleno derecho humano se debe consolidar para ser un instrumento fundamental para el reconocimiento de la igualdad de todas y cada una de las personas; contra cualquier tipo de discriminación o exclusión, así como para "una revaloración de la diversidad cultural frente a los intentos de homogeneización del mercado y el consumo" (Toledano Morales, 2009). 
Esta revista forma parte del acervo de la Biblioteca Jurídica Virtual del Instituto de Investigaciones Jurídicas de la UNAM

En este contexto, se tiene que concebir al derecho a la educación como un instrumento de justicia que procure mitigar las desigualdades entre los seres humanos, con independencia de su condición económica, social, ideológica, género, etnia o religión y se consolide como la base de desarrollo, progreso y bienestar (Toledano Morales, 2009). En síntesis, podemos argumentar que la educación es el mejor y más eficiente "elevador y nivelador social".

Este reconocimiento se ha venido gestando de manera reciente y es el resultado de un largo proceso histórico que significa ahora una renovación cultural e ideológica en esta era de modernidad (Martínez de Pisón, 2003).

Si bien es cierto que el derecho a la educación hoy en día ha sido adoptado por la mayoría de los países del mundo occidental y está ampliamente previsto en una gran parte de las Constituciones, así como en las convenciones y tratados internacionales relativos a derechos humanos, la cuestión es que se le sigue considerando como parte de los derechos económicos, sociales y culturales y, por tanto, su aplicación está sujeta a múltiples factores económicos, políticos e ideológicos., surgiendo el problema de que dejan a la educación dependiendo de una condición de viabilidad y restringida por esos aspectos, así como de la capacidad y voluntad de los gobernantes de invertir recursos financieros suficientes para el cumplimiento de sus fines.

La educación - entendida primero como derecho social y ahora como derecho humano - se ha venido transformando en una conquista histórica, fruto de tensiones, de luchas, de iniciativas de todo tipo y también de un desarrollo doctrinal no exento de polémicas (Martínez de Pisón, 2003).

La intención de estas reflexiones es concitar el acuerdo entre los académicos y especialistas del derecho constitucional, para arraigar la idea de que el derecho a la educación debe dejar de ser considerado un derecho social sujeto a las determinaciones políticas, económicas e ideológicas de los gobiernos de los Estados, para consolidarlo como un derecho humano, fundamental, que debe ser respetado por el Estado, quien debe asumir responsabilidades plenas para hacer efectivo su acceso y disfrute.

El derecho a la educación tiene que ser comprendido y aceptado como un derecho de carácter habilitante de las personas, indispensable para poder lograr el conocimiento, comprensión, ejercicio y defensa de todos los demás derechos inherentes a la condición humana. 
Esta revista forma parte del acervo de la Biblioteca Jurídica Virtual del Instituto de Investigaciones Jurídicas de la UNAM

La educación es un derecho que posibilita, una vez adquirido el conocimiento por una persona, el entendimiento, el ejercicio, la activación y la defensa de todas las demás garantías y derechos que están concebidos y aceptados por las constituciones y tratados internacionales. El reconocimiento de la educación como un derecho humano, lo convierte en un derecho vinculante, exigible, susceptible de hacerse valer a través de los procedimientos constitucionales de defensa.

De esta manera, las demandas para hacer valer al derecho a la educación ante los tribunales federales estarán justificadas y serán legítimas y, por tanto, los gobiernos se verán obligados por los efectos de las acciones justiciables y comprometidos a hacerlos efectivos.

Consolidar el derecho a la educación como derecho humano será sin duda una tarea compleja, debido a que las condiciones financieras imperantes en los países frenan su viabilidad y no basta con que se acepte su condición de derecho humano para que sea una realidad plena, pues requiere que el Estado proporcione su viabilidad financiera, cuestión difícil y onerosa.

Resulta impostergable su aceptación como derecho humano y fundamental, a efecto de poder demandarle al Estado el cumplimiento de las obligaciones constitucionales establecidas en el artículo 3o. de nuestra Carta Magna, que considera como responsabilidad del Estado impartir toda la educación, desde prescolar hasta el nivel superior.

El 15 de mayo de 2019, se publicó en el Diario Oficial de la Federación el decreto por el que se reformaron, adicionaron y derogaron diversas disposiciones de los artículos: 3o., 31 y 73 de la Constitución Política de los Estados Unidos Mexicanos.

Dese hace años se ha pretendido la cobertura total en diferentes niveles educativos. En 1934 se definió que la instrucción primaria sería obligatoria, lo mismo para la secundaria (1993), el prescolar (2003), la educación media superior (2012) y a últimas fechas la educación inicial y superior (2019).

Antes de comentar la reforma de 2019, vale la pena recordar que la misma mantiene una posición diferente a la que se había establecido en 2013. En esta última, además de reformarse el artículo 3o. constitucional, se modificó la Ley General de Educación, la Ley del Servicio Profesional Docente y se creó la ley que dio autonomía al Instituto Nacional de Evaluación Educativa. En términos genéricos, el nuevo régimen ponía a 
Esta revista forma parte del acervo de la Biblioteca Jurídica Virtual del Instituto de Investigaciones Jurídicas de la UNAM

la evaluación como eje del sistema educativo nacional bajo el supuesto de que incrementaría la calidad y se presentó como una actividad permanente, formativa y adecuada para la profesionalización de los docentes. El ingreso al servicio docente sería por concursos de oposición diseñados por el INEE, pudiéndose postular profesionales no egresados de la Escuela Normal. La permanencia en el servicio se vinculó a las evaluaciones obligatorias cada cuatro años.

Con la reforma de 2019 los anteriores aspectos quedaron inactivos. Se volvió a modificar el artículo 3o. constitucional, añadiéndosele varios conceptos. Así, por ejemplo, se estableció con claridad que toda persona tiene derecho a la educación y que el Estado deberá impartir y garantizar la educación inicial, preescolar, primaria, secundaria, media superior y superior.

En el texto de la reforma se señaló que para dar cumplimiento al principio de obligatoriedad de la educación superior se deberán incluir los recursos necesarios en los presupuestos federal, de las entidades federativas y de los municipios; y de forma adicional, se tendrá que establecer un fondo federal especial que asegure a largo plazo los recursos económicos necesarios para garantizar la obligatoriedad de los servicios educativos a nivel superior, así como la plurianualidad de la presupuestación de recursos financieros para el fortalecimiento de la infraestructura. ${ }^{4}$

Se retomó la idea que la educación debe ser obligatoria, universal, inclusiva, pública, gratuita y laica. Se señaló, igualmente, que la educación se basará en el respeto irrestricto de la dignidad de las personas, con un enfoque de derechos humanos y de igualdad. Además, fomentará en el ser humano el respeto a todos los derechos.

El texto de la reforma constitucional que establece la obligación del Estado de garantizar la impartición integral de la educación - es decir, en todos los niveles - está incluido en la parte dogmática del texto fundamental, lo cual no es menor, ya que constituye una muestra más que confirma que en México el derecho a la educación dejó de ser considerado como Derecho Social y se ha transformado y reconocido como un derecho humano y fundamental pleno, exigible y justiciable.

4 Artículos décimo segundo y décimo quinto transitorios del decreto por el que se reforman, adicionan y reforman diversas disposiciones de los artículos: $30 ., 31$ y 73 de la Constitución Política de los Estados Unidos Mexicanos en materia educativa, publicado en el Diario Oficial de la Federación el 15 de mayo de 2019. 
Esta revista forma parte del acervo de la Biblioteca Jurídica Virtual del Instituto de Investigaciones Jurídicas de la UNAM

Estos cambios constitucionales configuran un gran reto para el gobierno mexicano tendiente a ampliar el acceso de más jóvenes a estos niveles educativos superiores.

La obligatoriedad del derecho humano a la educación en México no sólo se basa en las disposiciones constitucionales, sino también en determinaciones convencionales. El párrafo primero del artículo XII de la Declaración Americana de los Derechos y Deberes del Hombre, a la letra dice: "Toda persona tiene derecho a la educación, la que debe estar inspirada en los principios de libertad, moralidad y solidaridad humanas" (Declaración Americana de los Derechos y Deberes del Hombre, 1948).

Sergio García Ramírez sostiene que la doctrina interamericana ha experimentado un importante desarrollo en lo concerniente al control de la convencionalidad, pues las sentencias de la Corte Interamericana de Derechos Humanos tienen la fuerza de una declaración o condena jurisdiccional; en otros términos, revisten eficacia vinculante, no únicamente orientadora o recomendatoria, porque además la Corte sostiene que esta atribución de control concierne no sólo a los tribunales, "sino [también] a cualquiera órganos o agentes del Estado" (García Ramírez, 2018).

El principio de la Convencionalidad, que ha sido adoptado por muchos Estados — como México, por ejemplo- consiste en considerar que tienen el mismo nivel jerárquico las normas constitucionales nacionales y las que emanan de los Tratados Internacionales que hayan sido suscritos y ratificados de manera debida. Entonces, el derecho humano a la educación no debería tener discusión alguna.

La importancia que tiene la aplicación del derecho humano a la educación en beneficio de las personas, así como para la sociedad entera, ha quedado manifiesta con motivo de la terrible pandemia que azota al mundo en estos tiempos.

Los efectos mortíferos que está dejando a su paso en el mundo la propagación del COVID-19, demuestran que los gobiernos de todas las naciones - aun las más desarrolladas - no han invertido recursos financieros suficientes para el desarrollo de la educación, ciencia y tecnología.

En México, un estudio reciente del Centro Regional de Investigaciones Multidisciplinarias de la UNAM, indica que de las personas fallecidas — de acuerdo con los certificados de defunción, hasta el pasado 27 de mayo - el $71 \%$ de las personas que murieron víctimas del virus, tenía una escolaridad de primaria o menos. 
Esta revista forma parte del acervo de la Biblioteca Jurídica Virtual del Instituto de Investigaciones Jurídicas de la UNAM

La desigualdad y la injusticia social, dentro de cualquier sistema político y social, se vuelven más lastimosas y lacerantes cuando se relacionan con la falta de acceso real e igualitario a la educación y a la salud, porque se les agrega la ecuación entre educados e ignorantes.

\section{CONCLUSIONES}

Tenemos que trabajar para lograr un gran consenso entre los académicos e intelectuales - de manera especial entre los constitucionalistas - para fortalecer la categoría de derecho humano que tiene la educación y sacarlo de la larga fila de derechos que se han concebido en los últimos tiempos.

Entre los estudiosos de la teoría de la constitución, debe existir la convicción de que de la misma manera como se justificó en la Constitución de 1857 la necesidad de inclusión en el texto constitucional de los mecanismos para hacer valer y defender los derechos garantizados en la misma carta magna — a través del juicio de amparo-; y después en la Constitución de 1917 la concepción y adopción de los derechos sociales; ahora se necesita que el derecho humano a la educación sea enarbolado, levantado en alto, priorizado, para que se acepte y comprenda que de nada sirve tener una larga lista de derechos y garantías, si la mayoría de la sociedad carece de elementos y herramientas cognoscitivas para conocerlos, acceder a ellos, entenderlos, ejercerlos y defenderlos cuando las instancias gubernamentales se los nieguen o conculquen.

Es preciso ubicar al derecho humano a la educación en un lugar primordial, de manera inmediata después de los derechos a la vida y la libertad, ya que siguiendo el hilo conductor de lo que venimos sosteniendo, la vida de las personas pierde sentido si no es posible vivirla con dignidad; y la libertad pierde su esencia, si no se ejerce y disfruta a plenitud de derechos.

$\mathrm{Y}$ es que el derecho humano a la educación les permite a las personas vivir con dignidad y ejercer la libertad en todos sus aspectos posibles, así como también de poder disfrutar de la seguridad jurídica, propiedad y de las demás concepciones de derechos y garantías. Como Corolario, como dice el filósofo español Fernando Savater: "La educación es el primer paso para la libertad". 
Esta revista forma parte del acervo de la Biblioteca Jurídica Virtual del Instituto de Investigaciones Jurídicas de la UNAM

\section{FUENTES CONSULTADAS}

BARRow, R. (2006). Los romanos, 2a. ed. México: Fondo de Cultura Económica.

Bowen, J y Hobson, P. (1997). Teorías de la educación. Innovaciones importantes en el pensamiento educativo occidental. México: Editorial Limusa.

BRENDA, E. (1996). Manual de derecho constitucional. España: Instituto Vasco de Administración Pública Marcial Pons.

Contreras, R. (2015). Teoría de la constitución. 7a. ed. México: Porrúa.

Comité de Derechos Económicos, Sociales y Culturales (1999). Observación general 13. El derecho a la educación (artículo 13 del Pacto). Suiza. ONU. Disponible en: https://www.right-to-education.org/es/resource/observaciones-generales-13-el-derecho-la-educaci-n-art-culo-13.

Declaración Americana de los Derechos y Deberes del Hombre (1948), disponible en: http://www.oas.org/es/cidh/mandato/Basicos/declaracion.asp.

Gadotti, M. (2003). Historia de las ideas pedagógicas. 4a. ed. México: Siglo XXI.

GARCÍA, A. (2015). Los derechos económicos, sociales, culturales y ambientales (DESCA) como derechos exigibles en el nuevo constitucionalismo latinoamericano. México: Comisión Nacional de los Derechos Humanos.

GarcíA, M. (1984). Derecho constitucional comparado. España: Tirant lo Blanch.

GARCÍA, M. (1989), Las transformaciones del Estado contemporáneo. España: Alianza Editorial.

GARCÍA, S. (2018). Panorama de la jurisprudencia interamericana sobre derechos humanos. México: CNDH.

Gargarella, R y Etchicury, H. (2011). La Constitución en 2020, 48 propuestas para una sociedad igualitaria. Argentina: Siglo XXI.

HAURIOU, A. (1980). Derecho constitucional e instituciones politicas. España: Ariel.

FERRAJOLI, L. (2010). Derecho y razón. 2a. ed. España: Trotta. 
Esta revista forma parte del acervo de la Biblioteca Jurídica Virtual del Instituto de Investigaciones Jurídicas de la UNAM

JAEGER, W. (2001). Los ideales de la cultura griega. México: Fondo de Cultura Económica.

JAEGER, W. (2008). Cristianismo primitivo y paideia griega. México: Fondo de Cultura Económica.

LuZuriaga, L. (1971). Historia de la educación y de la pedagogía. 9a. ed. Argentina: Editorial Losada.

MARTÍNEZ DE PISÓN, J. (2003). El derecho a la educación y la libertad de enseñanza. España: Instituto de Derechos Humanos Bartolomé de las Casas de la Universidad Carlos III de Madrid.

MARTínEZ, V. (2013). "Reflexiones sobre la dignidad humana en la actualidad". Boletín Mexicano de Derecho Comparado.

PÉREZ, A. (2017). Derechos humanos, Estado de derecho y Constitución. 11a. ed. España: Tecnos.

RizVi, F y Lingard, B. (2013). Políticas educativas en un mundo globalizado. España: Morata.

SAnTos, B. (2015). La Universidad en el siglo XXI. México: Siglo XXI.

SAntos, M. (2009). Politicas educativas y compromiso social. El progreso de la equidad y la calidad. España: Ministerio de Educación, Política Social y Deporte.

Schleicher, A. (2018). Primera Clase. Cómo construir una escuela de calidad para el siglo XXI. España: OCDE y Fundación Santillana.

Schmitt, C. (1992). Teoría de la Constitución. España: Alianza Editorial.

Toledano, R. (2009). "La equidad como principio y política social. Análisis de sus implicaciones en educación básica". Tiempo de educar. 10(20). ISSN: 1665-0824. Disponible en: https://www.redalyc.org/ar ticulo.oa? id $=31112987003$.

ToynBeE, A. (1981). Estudio de la historia. 6a. ed. España: Alianza Editorial.

UNESCO. (2015). Replantear la educación: ¿Hacia un bien común mundial? Francia: UNESCO. Disponible en: https://unesdoc.unesco.org/ ark:/48223/pf0000232697.

VAlEnCiA, S. (2003). Derecho, autonomía y educación superior, México, UNAM. 
Esta revista forma parte del acervo de la Biblioteca Jurídica Virtual del Instituto de Investigaciones Jurídicas de la UNAM

VARGAS, C. (2017). El aprendizaje a lo largo de toda la vida desde una perspectiva de justicia social. Francia: UNESCO. Disponible en: htt ps://es.unesco.org/node/262744.

Vergara, F. (1989). La paideia griega. Universitas Philosophica. 